\title{
Factors Affecting the Application of the PBB Model: Review on the Theoretical Framework
}

\author{
Vo Van NHI ${ }^{1}$, Mai Thi Hoang MINH ${ }^{2}$ and Le Thi Cam HONG ${ }^{3^{*}}$ \\ 1,2,3 School of Accounting, University of Economics Ho Chi Minh City \\ *Corresponding Author: hongltc@ueh.edu.vn
}

\begin{abstract}
The financial concern of managers at all levels is making decision based on the firm's budgeting information. Indeed, management accounting is the process of identifying, measuring, analyzing, interpreting and communicating information to managers for the pursuit of an organization's goals. One of the important techniques of management accounting is to involve the budgeting in guiding entities manage and use resources effectively. Currently, the most popular innovation trend in the public sector is performance-based budgeting (PBB). However, this budgeting model has not been widely applied in Vietnam and the application of the PBB model in other countries around the world is still facing many difficulties. Therefore, this article is trying to summarize previous studies and then using the theoretical background to study and predict the impact of contributing factors of the PBB application in the public entities in different countries.
\end{abstract}

\section{Research purpose:}

Research on the model of factors affecting the application off the PBB model according to the theoretical framework.

\section{Research motivation:}

Nowaday, performance-based budgeting $(P B B)$ is the most popular innovation trend in the public sector to help entities manage and use resources effectively. However, this budgeting model has not been widely applied in Vietnam and the application of the PBB model in other countries around the world is still facing many difficulties.

\section{Research design, approach and method:}

Summarize previous studies and then using the theoretical background to study.

\section{Main finding}

Construct an integrated research framework to study the most general contributing factors of the application of PBB

\section{Practical/managerial implication:}

This result serves as a theoretical basis for conducting a follow-up study, which could provide more empirical evidences for the impact of these factors in the context of research concerning public institutions in Vietnam.

Keywords: budgeting, Performance-based budgeting, performance budgeting, outcome-based budgeting.

\section{INTRODUCTION}

The trend of reforming the accounting and budgeting systems is taking place around the world to help reduce budget imbalances, prevent corruption and increase the efficiency of budget spending in countries such as the United States, New Zealand, UK, Australia, Netherlands, Sweden, etc. (Ouda, 2010). The budgeting study is an important part of a series of studies on reforming the state accounting system in the New Public Management (NPM) era (Chan, Jones, \& Lüder, 1996).

In addition, the studies on performance - based budget management reform show that this trend has changed the budgeting method in the direction of applying the PBB model in countries, which is an inevitable trend, but it takes time and is influenced by many factors.
This innovation process requires participants' awareness which is an important determinant of the success of the innovation process (Hepworth, 2003).

Moreover, the application of PBB is influenced by many different factors in the context of different countries, as well as the context and conditions of application are different, so there are countries that succeed as well as there are countries that fail in reforming to PBB (J. Melkers \& Willoughby, 1998).

Therefore, the objective of this study is to study a model based on the theoretical framework of factors affecting the adoption of PBB. This theoretical model developed during the implementation phase of $\mathrm{PBB}$ is drawn from studies on the application of PBB in different contexts to identify a model that combines different factors (such as: Premkumar and Roberts 
(1999); Adler, Everett, and Waldron (2000); Julnes and Holzer (2001); Y. I. Lu (2007); so on)

\section{CONCEPTS}

According to Mauro, Cinquini, and Grossi (2017), PBB is a performance information-based budgeting model in which entities use performance information for budgeting process and resource allocation (the United Stated General Accounting Office).

In other word, performance-based budgeting is a method of budgeting based on accessing information about output results to allocate and evaluate the use of financial resources to aim at achieving development strategy target of the government (Thành, 2005). Specifically, output is understood as public goods or services created and provided by state agencies and entities to society; while performance or outcome is the impact on the community from the process of creating an output or group of outputs (Kibblewhite \& Ussher, 2002). On the other hand, the concept of performance is a complex concept that can be viewed from many different angles (Van Dooren, Bouckaert, \& Halligan, 2015). In public sector research, performance is a multi-dimensional concept that is considered from concerns about efficiency, effectiveness, quantity and quality of output, productivity, equity, balance, and meeting service demand, trust and satisfaction of residents and consumers (J. Lee, 2008; Walker et al. .2011). Therefore, performance concept in this study is determined based on the output with the size of the entity's operations and combined with the desired outcome of the government. Thereby, PBB is the process of collecting and preparing budgeting based on performance information to allocate and evaluate the use of financial resources by public entities to achieve the development strategy target of the government in general and public entities in particular. In this study, PBB is considered from the perspective of a financial and budgetary information system, that is, the process of collecting, processing, storing, providing data and information about finance and budget as well as provide feedback to achieve the entities's goals.

\section{OVERVIEW OF STUDIES RELATED TO FACTORS AFFECTING THE APPLICATION OF PBB}

A number of studies around the world have shown the influence of factors related to institutional characteristics (including: authority and capacity) as well as perceived benefits of PBB to the application of PBB through studies conducted in different countries such as Carlin and Guthrie (2001) conducted in Australia and New Zealand or Syukri (2005) conducted in Indonesia, or Julnes and Holzer (2001) demonstrated the influence of political and cultural factors on the use of performance information.

In addition, the trend of management reform based on performance has changed the method of budgeting that use the performance information for budgeting in public entities, so a number of other studies, such as: Premkumar and Roberts (1999), Kluvers (1999), Kim and Kankanhalli (2009), etc. demonstrated the influence of factors related to public entities - that is, organizational support; or Grizzle and Pettijohn (2002), Andrews (2004), Niu, Ho, and Ma (2006), Y. I. Lu (2007), Erkutlu, Tanç, and Koçyiğit (2017), etc. demonstrated the influence of institutional authority and capacity on the adoption of PBB in public entities.

At the same time, some other studies also show the influence of perceived factors on the relative advantage of $\boldsymbol{P B B}$ and on the self-efficacy of the estimators and the factors hindering the application of $\mathrm{PBB}$ in relation to swiching cost are demonstrated through Adler et al. (2000) or Kim and Kankanhalli (2009) or Ehsein (2014), Aliabadi, Mashayekhi, and Gal (2019), so on.

The review process of previous studies shows that PBB is an appropriate model and an inevitable trend, but the application of PBB is still not effective (H. Lu, 1998; Moynihan, 2006) in which the assessment effectiveness of using budget in the budgeting process is not clear, many budget committees do not use the performance for decision making (J. E. Melkers \& Willoughby, 2001). Therefore, the awareness of the benefits of PBB helps managers improve efficiency in public sector budget management, but the application of PBB still faces certain obstacles related to the adaptability of the estimators, as well as the authority for application and the capacity of the institution itself. Especially for public entities, the organizational support, awareness of the benefits of PBB as well as the capacity of the estimator to change will contribute to the successful application of PBB.

\section{THEORETICAL BACKGROUND}

Budgeting is one of the techniques of management accounting, and is therefore influenced by various factors including organizational factors, behavioral factors, economic and social factors. Therefore, when studying issues related to management accounting in general and budgeting techniques in particular, researchers have relied on different theoretical perspectives to describe the impact relationship of factors in different aspects, in which there are a few typical theories that are often applied to research such as contingency theory of organization, agency theory, social psychology theory... This article applies some theoretical backgrounds to study the impact relationship of the above factors related to the application of the PBB model in public entities, which includes factors such as awareness of the relative advantage of PBB, swiching cost, self-efficacy for change, organizational support, the authority for application and the capacity of the institution are related to three important theories: The Theory Of Planned Behavior, Status Quo Bias Theory, And New Institutional Sociology Theory. 


\subsection{Theory of planned behavior-TPB (Ajzen, 1991)}

Ajzen (1991) from Theory of reasoned ation - TRA formulated by Ajzen and Fishbein in 1967, developed the theory of planned behavior - TPB is a form of psychological theory. Ajzen (1991) reflects three factors affecting human behavior, in this study is the behavior of applying PBB on the basis of factors from TRA, including: attitude, subjective norms and perceived behavioral control. TPB believes that a person's actual behavior will be determined by the intention to perform that behavior, in which the attitude expressed by the belief that performing the behavior is useful, the subjective norm represents the perception of the expected norms of others and the motivation to conform to those expected norms, influencing the individual's perception of whether or not to perform the behavior, and perceived behavioral control is a factor expressed through the perceived ease or difficulty of performing the behavior, these perceived behavioral control factors include: one's capabilities, resource and technology favorable conditions that help control perceived behavior (Ajzen, 2002). Based on the views of Ajzen (1991), Taylor and Todd (1995) have continued to study the decomposed model of the TPB based on the diffusion of innovation theory to have better explanatory power than the pure TPB and TRA model, see Figure 1.

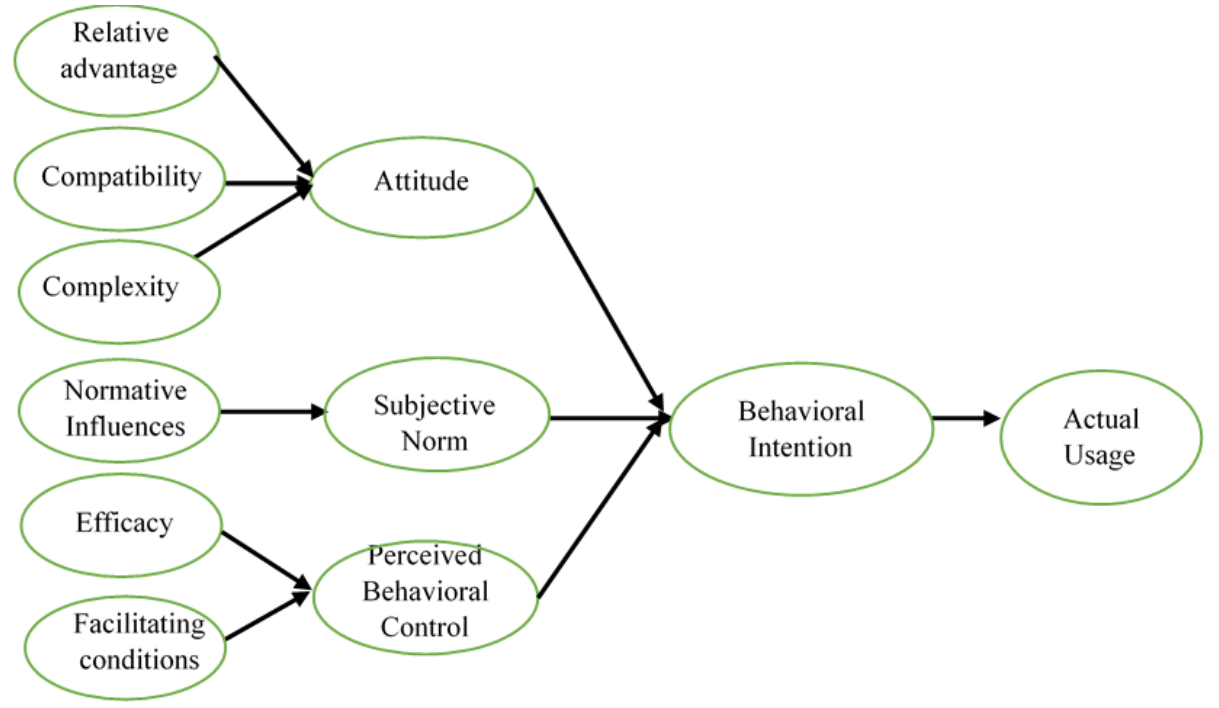

Figure 1. The theory of planned behavior with belief decomposition (Taylor \& Todd, 1995)

\subsection{Status Quo Bias Theory - SQB theory (Samuelson \& Richard, 1988)}

The concept of "status quo bias" was first defined by William Samuelson and Richard Zeckhauser in "status quo bias in decision making" in 1988. The status quo bias theory of Samuelson and Richard (1988) aims to explain people's preference for maintaining their current status without accepting innovation from three perspectives: rational decision making, cognitive misperceptions and psychological commitment. Rational decision making implies an assessment of relative costs and benefits of change when moving to a new alternative; the cognitive misperception of loss aversion is a psychological principle that has been observed in human decision making (Kahneman \& Tversky, 1979), loss aversion can result in status quo bias; Psychological commitments are states of psyche, strong sense of intention including factors influencing the decision to continue to maintain the status quo. Therefore, applying SQB theory to consider the cognitive factors that hinder the behavior of applying innovation.

Therefore, in the scope of the article with the aim of explaining the reasons that prefer to maintain the current status (traditional budgeting) leading to the resistance to the application of innovation (PBB) of the participants, the author applies the $S Q B$ theory to consider and prove the impact of the barrier factors in the estimators' perception - that is, the switching costs on the behavior of applying innovation.

\subsection{New Institutional Sociology - NIS}

NIS is a new stream of institutional theory (Hall, Taylor, \& Taylor, 1996) that has frequently been applied in research related to management accounting to explain how rules, norms, structures, and belief systems reshape organizations (Burns \& Scapens, 2000; Scott, 2008). According to NIS, culture, social beliefs and values affect organizational behavior (Meyer \& Rowan, 1977). Covaleski and Dirsmith (1988) argue that NIS can be used to explain the relationship between management accounting practices in a social organization and its institutional environment. In general, it is the conformity between the conditions for implementing innovation and the requirements of the institution that will promote the behavior of innovation adoption. Especially, the theory of Institutional Isomorphism developed by DiMaggio and Powell (1983) from isomorphism theory of Hawley (1968) refers to three factors including Coercive Isomorphism, Mimetic Isomorphism, Normative Isomorphism. Coercive Isomorphism comes from the "pressures exerted on the organization by other 
organizations, upon which they are dependent and by cultural expectations in the society within which the organizations function" (DiMaggio \& Powell, 1983, p. 150). Mimetic isomorphism originates from the response to uncertainty. When the objective is unclear, and the environment is uncertain, a organizations tend to follow the model of another organizations, although it may have originated from a different culture (DiMaggio \& Powell, 1983; Scott, 2008). Normative Isomorphism occurs when an organization adopts a model because of the pressure of professionalization, that is, members of a profession jointly manage quality and establish a cognitive and regulatory basis for occupational autonomy (Larson, 1977 quoted in DiMaggio \& Powell, 1983). Thereby, according to the institutional isomorphism theory, the suitability of the institution with the PBB represents the compatibility of the $\mathrm{PBB}$ with the institutional characteristics that will affect the behavior of applying $\mathrm{PBB}$, so in the scope of this study, the apply this theory to study the impact of "institutional authority and capacity" on PBB adoption behavior.

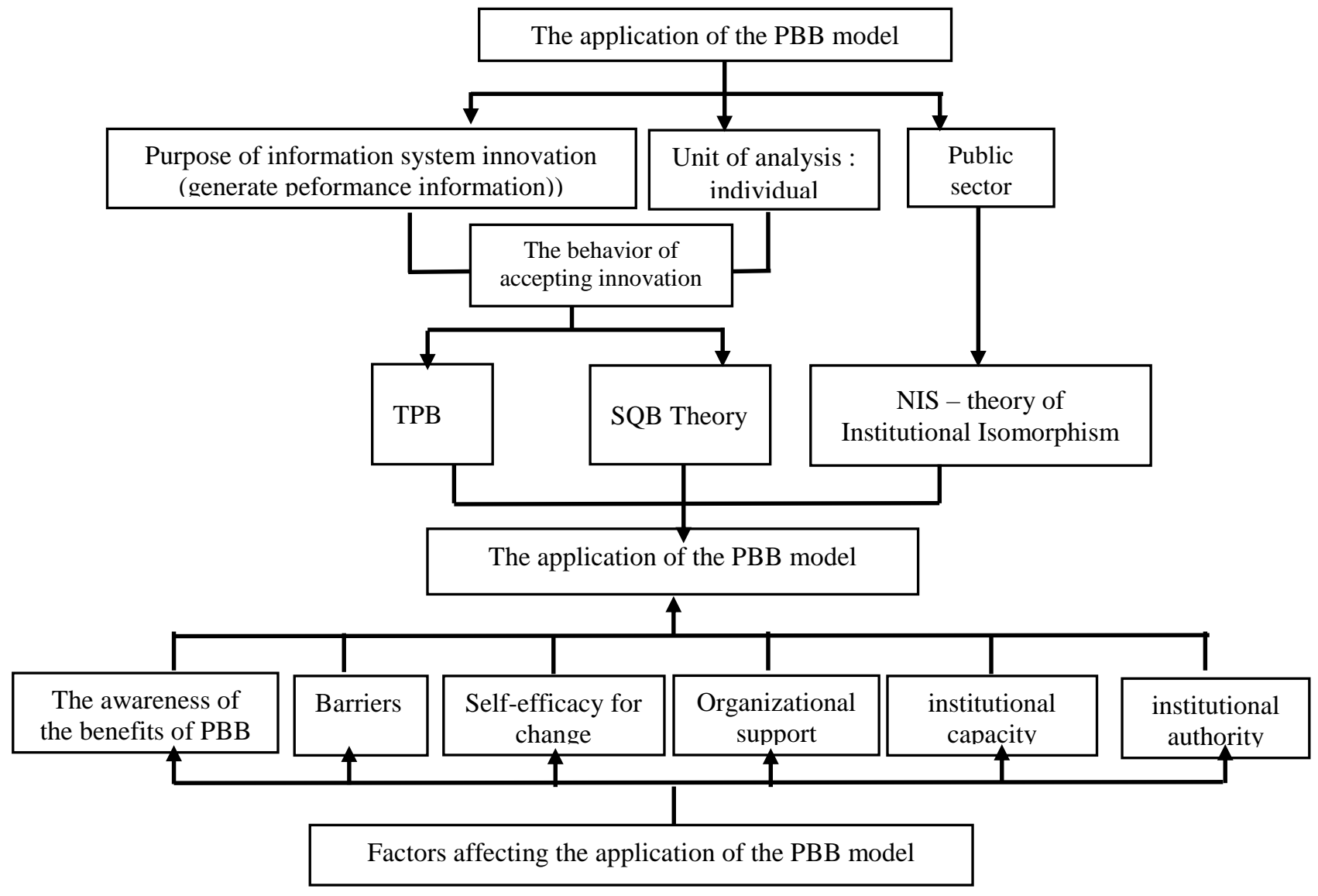

Figure 2: Synthesis of theoretical background.

\section{INTEGRATIVE THEORETICAL FRAMEWORK}

Based on the above-mentioned theoretical background related to the analysis of factors affecting the adoption of innovation - in the case of PBB application. User awareness is crucial in accepting any innovation, which can lead to innovation success. This study uses TPB, as an important theoretical framework in technology acceptance research, and applies other theories to explain the impact of other factors on the adoption of PBB. In this way, it helps to broaden research related to user acceptance and resistance, and to improve understanding of PBB-related change.

First of all, according to TPB, attitude towards a behavior is the degree to which performance of the behavior is positively or negatively valued (Ajzen, 2002). Attitudes will be positive if the behavior is perceived to offer a relative advantage or value over than the individual's current situation. Accordingly, the attitude is represented by the perceived relative advantage of PBB in this study, at the same time corresponds to the net benefit concept in rational decision-making explanation of the status quo bias.

In this study, the perceived value of benefits and costs is considered to be the perceived relative advantage of PBB and switching costs. While relative advantage implies the utility associated with switching to a new alternative, switching costs refer to the disutility associated with switching (Chen \& Hitt, 2002). At the same time, "switching costs" in SQB theory include transition costs, uncertainty costs, and sunk costs.

Second, TPB's perceived behavioral control (corresponding to SQB's control) considers both internal and external controls. In which, self-efficacy 
and organizational support for change respectively represent the internal and external means of achieving control over the changed situation (Ajzen, 2002).

Third, the research problem is related to the public sector, so it will be governed by institutions, that is, the difference in conditions and environment in the application of PBB among public entities in Vietnam, and institutional differences between countries, so when looking at the factors affecting the application of PBB in public non-business entities in Vietnam, it is necessary to consider institutional factors to see the compatibility of innovation, including: law, authority, capacity foundation, culture. In particular, Vietnam has now had many significant changes in administrative reform, such as changes in the budget law, public property management law, public investment law, etc., these remarkable efforts have supported and create favorable conditions for information system innovation for application PBB. These changes indicate that it is appropriate to change the budgeting model, but are these changes enough to affect the behavior of the estimator? Therefore, this study has added the factors of "institutional capacity" and "institutional authority" to the research model based on the impact perspective of NIS theory - institutional isomorphism, and the perspective of the public sector institutional model, to consider together with the factors of TPB's perceived behavioral

\section{SOB Theory}

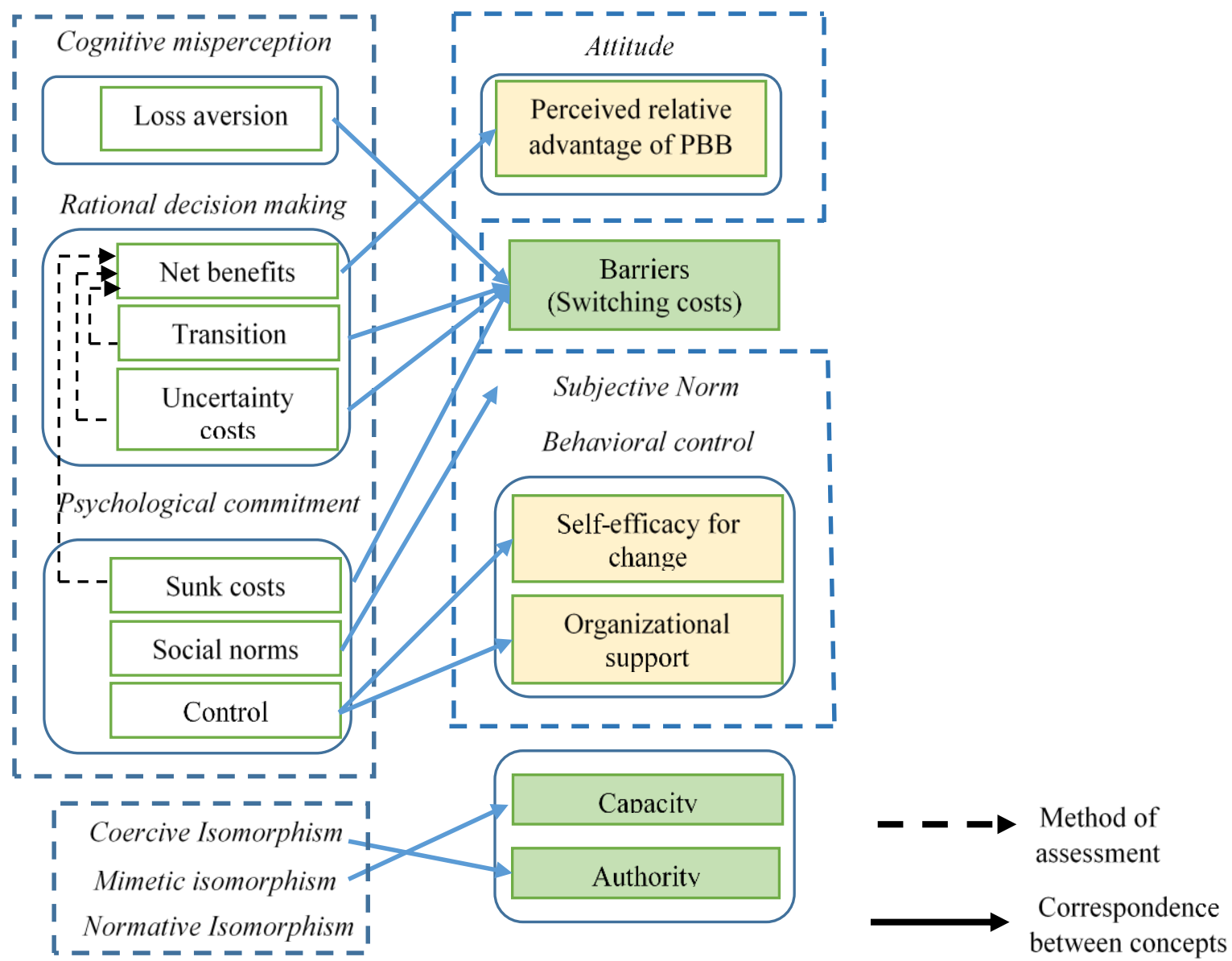

NIS - theory of Institutional Isomorphism

Public sector institution model

TPB

Figure 3. Integrative theoretical framework

\section{CONCLUSION}

The research related to $\mathrm{PBB}$ tends to apply many integrated theoretical background to examine scientific phenomena in which the commonly applied theories are new institutionalism theory, agency theory, agency theory combines organizational learning theory and political behavior theory, psychological theory (Mauro
Source: Author's own compilation et al., 2017), looking through multiple-theoretical perspectives helps to provide deeper insights and explain scientific phenomena in theoretically convincing manner. Many fundamental theories have been identified through the literature review process to explain the impact relationship of factors on the application of the PBB model. In which, the integration 
of three theories such as the theory of planned behavior - TPB, status quo bias theory and the new institutional theory - can almost give the most general explanation for the impact relationship of factors affecting the application of PBB. TPB is applied as an important theoretical framework to explain the impact relationship of "perceived relative advantage of PBB", "self-efficacy" and "organizational support" to the application of PBB. In addition, the SQB theory also supports the impact relationship of " self-efficacy " and "organizational support" and further explains the impact relationship of "switching costs" on the application of PBB. Finally, the institutional isomorphism theory helps identify the impact relationship of "institutional capacity" and "institutional authority" to the application of PBB. In general, the factors affecting the application of PBB have been explained and supported by theoretical background through many studies in many different research contexts. Based on the views of the above studies, this article has been integrated into an integrated research framework to study the most general influencing factors for the application of PBB. However, it is necessary to conduct a follow-up study to provide more empirical evidence for the impact of these factors in the context of research in public institutions in Vietnam.

\section{REFERENCES}

[1]. Adler, R. W., Everett, A. M., \& Waldron, M. (2000). Advanced management accounting techniques in manufacturing: utilization, benefits, and barriers to implementation. Paper presented at the As published in Accounting Forum.

[2]. Ajzen, I. (1991). The theory of planned behavior. Organizational behavior and human decision processes, 50(2), 179-211.

[3]. Ajzen, I. (2002). Perceived behavioral control, self-efficacy, locus of control, and the theory of planned behavior 1. Journal of applied social psychology, 32(4), 665-683.

[4]. Aliabadi, F. J., Mashayekhi, B., \& Gal, G. (2019). Budget preparers' perceptions and performance-based budgeting implementation. Journal of Public Budgeting, Accounting \& Financial Management.

[5]. Andrews, M. (2004). Authority, acceptance, ability and performance-based budgeting reforms. International Journal of Public Sector Management.

[6]. Burns, J., \& Scapens, R. W. (2000). Conceptualizing management accounting change: an institutional framework. Management accounting research, 11(1), 3-25.

[7]. Carlin, T. M., \& Guthrie, J. (2001). Lessons from Australian and New Zealand experiences with accrual output-based budgeting. In Learning from International Public Management Reform: Part A (pp. 89-100): JAI Press.

[8]. Chan, J. L., Jones, R. H., \& Lüder, K. G. (1996). Modeling governmental accounting innovations. Research in governmental and nonprofit accounting, 9, 1-19.

[9]. Chen, P.-Y., \& Hitt, L. M. (2002). Measuring switching costs and the determinants of customer retention in Internet-enabled businesses: A study of the online brokerage industry. Information systems research, 13(3), 255-274.

[10]. Covaleski, M. A., \& Dirsmith, M. W. (1988). An institutional perspective on the rise, social transformation, and fall of a university budget category. Administrative science quarterly, 562587.

[11]. DiMaggio, P. J., \& Powell, W. W. (1983). The iron cage revisited: Institutional isomorphism and collective rationality in organizational fields. American sociological review, 147-160.

[12]. Ehsein, A. J. (2014). Factors influencing the readiness to adopt performance based budgeting system (pbbs) among Libyan institutions of higher learning / Ali Jaballa Ehsein. In. Malaysia, Australia.

[13]. Erkutlu, H. V., Tanç, Ş. G., \& Koçyiğit, S. Ç. (2017). The Factors Used to Create Performance-Based Budgeting: A Research on Turkey. Accounting and corporate reporting, 297.

[14]. Grizzle, G. A., \& Pettijohn, C. D. (2002). Implementing performance-based program budgeting: a system-dynamics perspective. Public Administration Review, 62(1), 51-62.

[15]. Hall, P. A., Taylor, R. C. R., \& Taylor, R. C. R. (1996). Political science and the three new institutionalisms. Political Studies, 44(5), 936957.

[16]. Hepworth, N. (2003). Preconditions for successful implementation of accrual accounting in central government. Public Money \& Management, 23(1), 37-44.

[17]. Julnes, P. d. L., \& Holzer, M. (2001). Promoting the utilization of performance measures in public organizations: An empirical study of factors affecting adoption and implementation. Public administration review, 61(6), 693-708.

[18]. Kahneman, D., \& Tversky, A. (1979). Prospect theory: An analysis of decision under risk. Econometrica, 47(2), 263-291. 
[19]. Kim, H.-W., \& Kankanhalli, A. (2009). Investigating user resistance to information systems implementation: A status quo bias perspective. MIS quarterly, 567-582.

[20]. Kluvers, R. (1999). To PPB or not PPBbudgeting in Victorian local government. Australian Journal of Public Administration, 58(4), 68-77.

[21]. Lu, H. (1998). Performance budgeting resuscitated: Why is it still inviable? Journal of Public Budgeting, Accounting \& Financial Management, 10(2), 151-172.

[22]. Lu, Y. I. (2007). Performance Budgeting: The Perspective of State Agencies. Public Budgeting \& Finance, 27(4), 1-17.

[23]. Mauro, S. G., Cinquini, L., \& Grossi, G. (2017). Insights into performance-based budgeting in the public sector: a literature review and a research agenda. Public Management Review, 19(7), 911-931.

[24]. Melkers, J., \& Willoughby, K. (1998). The state of the states: Performance-based budgeting requirements in 47 out of 50. Public Administration Review, 66-73.

[25]. Melkers, J. E., \& Willoughby, K. G. (2001). Budgeters' views of state performancebudgeting systems: Distinctions across branches. Public Administration Review, 61(1), 54-64.

[26]. Meyer, J. W., \& Rowan, B. (1977). Institutionalized Organizations: Formal Structure as Myth and Ceremony. American Journal of Sociology, 83(2), 340.

[27]. Moynihan, D. P. (2006). What do we talk about when we talk about performance? Dialogue theory and performance budgeting. Journal of public administration research and theory, 16(2), 151-168.
[28]. Niu, M., Ho, A., \& Ma, J. (2006). Performancebased budgeting in China: A case study of Guangdong. Network of Asia-Pacific Schools and Institutes of Public Administration and Governance (NAPSIPAG), 410.

[29]. Ouda, H. A. G. (2010). A Prescriptive Model for Successful Transition to Accrual Accounting in the Government Sector. International Journal on Governmental Financial Management, 10(1).

[30]. Premkumar, G., \& Roberts, M. (1999). Adoption of new information technologies in rural small businesses. Omega (Oxford)(4), 467.

[31]. Samuelson, W., \& Richard, Z. (1988). Status Quo Bias in Decision Making. Journal of Risk \& Uncertainty, 1(1), 7-59.

[32]. Scott, W. R. (2008). Institutions and organizations: ideas and interests. Los Angeles: Sage Publications.

[33]. Syukri, H. (2005). Performance Based Budgeting: A Model for the Indonesian DOD. Retrieved from https://search.ebscohost.com/login.aspx?direct=t rue \&AuthType $=\mathrm{ip}, \mathrm{sso} \& \mathrm{db}=\mathrm{edsbas} \& \mathrm{AN}=$ edsbas A2C30C\&site $=$ eds-live $\&$ custid $=\mathrm{s} 3282651$

[34]. Taylor, S., \& Todd, P. A. (1995). Understanding Information Technology Usage: A Test of Competing Models. Information Systems Research, 6(2), 144-176.

[35]. Thành, S. Đ. (2005). Vận dụng phuoong thức lập ngân sách theo kết quả đầu ra trong quản lý chi tiêu công của Việt Nam (In lần thứ 1. ed.): Tài chính.

[36]. Van Dooren, W., Bouckaert, G., \& Halligan, J. (2015). Performance management in the public sector: Routledge. 